\title{
OCORRÊNCIA DE MASTITE SUBCLÍNICA OVINA DURANTE DUAS LACTAÇÕES CONSECUTIVAS EM REBANHO DA RAÇA SANTA INÊS
}

\section{OCCURRENCE OF OVINE SUBCLINICAL MASTITIS DURING TWO CONSECUTIVE LACTATIONS IN A SANTA INES BREED HERD}

\author{
Luiz Francisco Zafalon ${ }^{1}$ \\ Josir Laine Aparecida Veschi² \\ Katheryne Benini Martins ${ }^{3}$ \\ Raul Costa Mascarenhas Santana ${ }^{4}$ \\ ${ }^{1}$ Pesquisador Doutor da Empresa Brasileira de Pesquisa Agropecuária, Embrapa Pecuária Sudeste, São \\ Carlos, SP, Brasil - luiz.zafalon@embrapa.br \\ ${ }^{2}$ Pesquisadora Doutora da Empresa Brasileira de Pesquisa Agropecuária, Embrapa Semi-Árido, Petrolina, \\ PE, Brasil \\ ${ }^{3}$ Pós-graduanda da Universidade Estadual Paulista, Botucatu, SP. Brasil. \\ ${ }^{4}$ Analista da Empresa Brasileira de Pesquisa Agropecuária, Embrapa Pecuária Sudeste, São Carlos, SP, \\ Brasil
}

\section{Resumo:}

O objetivo desse estudo foi avaliar a ocorrência da mastite subclínica ovina em duas lactações e a evolução da doença em duas lactações consecutivas. As amostras de leite foram originadas de um rebanho com 160 ovelhas da raça Santa Inês. Na primeira lactação, colheram-se amostras em ovelhas aos 14 dias pós-parto e no período próximo ao desmame. Na segunda lactação, as amostras de leite foram colhidas dos mesmos animais aos 14 dias pós-parto, 52 dias pós-parto e ao desmame. A triagem dos casos de mastite subclínica foi feita preliminarmente por meio do California Mastitis Test (CMT). As amostras de leite para a investigação microbiológica foram obtidas de metades mamárias positivas e negativas ao CMT. Os estafilococos coagulase-negativos foram os micro-organismos de maior ocorrência nas duas lactações. Houve a predominância de ovelhas que permaneceram com mastite subclínica durante a Lactação 1. As curas espontâneas foram significativamente inferiores no período entre 52 dias de lactação e o desmame dos cordeiros. Nenhuma diferença foi observada quanto à evolução dos casos de mastite subclínica infecciosa quando comparadas duas lactações $(\mathrm{P}>0,05)$.

Palavras-chave: estafilococos; leite; mastite ovina.

\begin{abstract}
:
The aim of this study was to evaluate the occurrence of ovine subclinical mastitis in two lactations, and the disease evolution in two consecutive lactations. Milk samples originated from a herd with 160 Santa Inês breed sheep. In the first lactation, milk samples were collected from ewes at 14 days post-partum and during the period near weaning. In the second lactation, milk samples were collected from the same animals at 14 days postpartum, at 52 days postpartum and at weaning. Screening of
\end{abstract}


subclinical mastitis was carried out preliminarily by means of California Mastitis Test (CMT). Milk samples for microbiological culture were obtained from CMT-positive and CMT-negative mammary halves. Coagulase-negative Staphylococci were the most prevalent microorganisms isolated in two lactations. Ewes that remained with subclinical mastitis in lactation 1 were predominant. Spontaneous recoveries were significantly lower in the period between 52 days of lactation and weaning of lambs. No difference was observed regarding the progression of subclinical mastitis cases compared the two lactations $(\mathrm{P}>0.05)$.

Keywords: milk; ovine mastitis; Staphylococci.

Recebido em: 23 out. 2012.

Aceito em: 10 dez. 2014

\section{Introdução}

A mastite está entre as principais doenças que acometem os ovinos. Caracteriza-se por ser de difícil controle e por influenciar negativamente o bem-estar animal ${ }^{(1)}$, inclusive em animais da raça Santa Inês, que não são especializados para a produção de leite, mas apresentam uma maior aptidão leiteira quando comparados com animais de outras raças destinadas à exploração comercial da carne ${ }^{(2)}$.

A forma subclínica da mastite ovina apresenta relevância econômica, em virtude dos prejuízos na produção animal e da sua maior ocorrência quando comparada com a forma clínica da enfermidade $^{(3,4)}$. O leite das ovelhas acometidas apresenta redução significativa dos teores de gordura e proteína, que pode influenciar negativamente o desenvolvimento dos $\operatorname{cordeiros}^{(5)}$.

Nunes et al. ${ }^{(2)}$ relataram os estafilococos e estreptococos como predominantes na etiologia infecciosa da mastite ovina. Bolsanello et al. ${ }^{(6)}$ também descreveram estafilococos e estreptococos como os micro-organismos mais frequentes em ovelhas com mastite subclínica, dos quais os estafilococos coagulase negativa foram os de maior ocorrência.

O conhecimento da etiologia infecciosa da mastite oferece aos técnicos e produtores informações sobre o controle da doença, uma vez que métodos de prevenção podem ser diferentes de acordo com os micro-organismos. O objetivo deste estudo foi avaliar a ocorrência da mastite subclínica ovina em duas lactações e a evolução da doença em duas lactações consecutivas.

\section{Material e Métodos}

As amostras de leite foram oriundas de um rebanho de 160 animais localizado na região de São Carlos, São Paulo, com altitude média de $856 \mathrm{~m}$ ao nível do mar, temperatura e precipitação médias anuais entre 16,3 e $23{ }^{\circ} \mathrm{C}$ e $1.502 \mathrm{~mm}$, respectivamente.

As ovelhas foram criadas em sistema semi-intensivo, em uma área de 3,5 ha e em sistema rotacionado de pastejo em piquetes $\left(3.900 \mathrm{~m}^{2}\right.$ cada) de capim Panicum maximum cv. Aruana. As fêmeas foram suplementadas "a pasto" com silagem de milho na época seca do ano e no terço final da gestação. O rebanho era formado por ovelhas deslanadas da raça Santa Inês, submetidas a períodos de estação de monta natural controlada. Durante os primeiros dias pós-parto, as ovelhas foram mantidas em galpão coberto, com acesso a piquetes durante o dia. À noite eram recolhidas exclusivamente ao galpão, com 
o recebimento de suplementação alimentar com silagem de milho e/ou ração concentrada. O desmame ocorreu em torno de 90 dias pós-parto e as ovelhas faziam parte de um grupo de animais com, no máximo, quatro estações de monta.

As ovelhas foram submetidas ao exame físico do úbere antes da estação de monta e foram excluídas do estudo quando apresentaram quaisquer alterações condizentes com um quadro clínico de mastite. Na primeira lactação, denominada "Lactação 1", as amostras foram colhidas de todas as ovelhas paridas aos 14 dias pós-parto e no final do aleitamento, até três dias pós-desmame ${ }^{(7)}$, entre maio e setembro de 2009. Na segunda lactação, denominada "Lactação 2", as amostras de leite foram colhidas aos 14 dias pós-parto, 52 dias pós-parto e ao final do aleitamento, entre maio e novembro do ano seguinte à "Lactação 1 ".

Amostras de leite de todas as metades mamárias dos animais em lactação e ao desmame foram colhidas para a realização do California Mastitis Test (CMT), visando à classificação preliminar dos casos subclínicos de mastite. Para a leitura da prova foram misturados $2 \mathrm{~mL}$ de reagente a $2 \mathrm{~mL}$ de leite e verificou-se a intensidade da alteração da viscosidade da mistura ${ }^{(8)}$. A partir das metades mamárias CMT-positivas e negativas, alíquotas de 2 a $5 \mathrm{~mL}$ de leite foram colhidas assepticamente para os exames microbiológicos, após a antissepsia do óstio papilar com álcool etílico 70\% (v/v). Essas amostras foram obtidas em tubos de vidro esterilizados e em duplicatas, de cada glândula mamária e acondicionadas em recipientes com gelo, com posterior encaminhamento ao laboratório para o isolamento e a identificação microbiológicos.

A partir da amostra asséptica, foi semeado $0,01 \mathrm{~mL}$ de leite em ágar com 5\% de sangue ovino. Após a incubação a $37^{\circ} \mathrm{C}$, durante 24 a 72 horas, os micro-organismos foram identificados. Os cocos Grampositivos foram submetidos às provas da catalase e da coagulase lenta com plasma de coelho. Posteriormente, as cepas catalase e coagulase positivas foram submetidas à prova para verificação da produção de acetoína, cujas cepas que se mostraram positivas foram classificadas como Staphylococcus aureus, enquanto as negativas foram identificadas como estafilococos coagulase positiva. Os isolados negativos na prova da coagulase foram submetidos aos testes de resistência à furazolidona e de atividade da oxidase, para a diferenciação entre as bactérias dos gêneros Staphylococcus e Micrococcus ${ }^{(9)}$.

As colônias semeadas em ágar sangue e incubadas a $37{ }^{\circ} \mathrm{C}$ por 24 a 48 horas que se apresentaram pequenas, lisas, translucentes, circundadas por uma zona esverdeada ou clara de eritrócitos descoloridos ou células lisadas, respectivamente, reconhecidas como cocos Gram-positivos e negativas à prova da catalase foram classificadas como Streptococcus $\operatorname{spp}^{(9)}$.

As colônias circulares, brancas, cremes ou opacas em ágar sangue após 48 horas de incubação a $37{ }^{\circ} \mathrm{C}$ que se apresentaram como bastonetes Gram-positivos pleomórficos sob a forma de paliçada e "letras chinesas" foram analisadas quanto à produção de hemólise e submetidas à prova da catalase para diferenciação entre Corynebacterium spp. e Trueperella pyogenes ${ }^{(10,11)}$. As colônias cinzas e grandes após 24 horas de incubação a $37{ }^{\circ} \mathrm{C}$ e reconhecidas como bastonetes Gram-negativos foram identificadas como coliformes ${ }^{(9)}$.

A evolução da mastite subclínica foi estudada, classificando-se os casos da doença de acordo com a manutenção de metades mamárias reagentes ao CMT e identificação microbiológica do agente etiológico. Resultados conjuntos de positividade ao CMT e identificação microbiana foram obrigatórios para considerar uma metade mamária como positiva para a mastite subclínica. Consideraram-se como novos casos de mastite subclínica quando metades mamárias que não apresentaram isolamento microbiológico em um primeiro momento passaram a apresentá-lo. 
Classificaram-se as metades mamárias com cura espontânea quando, posteriormente, na segunda colheita de amostras, não foram isolados micro-organismos em metades anteriormente infectadas.

A evolução dos casos de mastite subclínica foi acompanhada dentro de uma mesma lactação ("Lactação 2") e nas duas lactações consecutivas. A confrontação das distribuições de frequência de cada tipo de evolução nos diferentes períodos estudados foi efetuada por meio do teste exato de Fisher $^{(12)}$.

\section{Resultados e Discussão}

Os estafilococos foram os micro-organismos mais isolados durante a Lactação 1 (Tabela 1). Aos 14 dias de lactação, do total de 63 mamas com mastite subclínica, em 54 (85,7\%) foram identificados estafilococos isoladamente ou em associação com outros micro-organismos, enquanto ao desmame estes micro-organismos estiveram presentes em $31(83,8 \%)$ de um total de 37 mamas, tanto isoladamente como em conjunto com outros micro-organismos.

Tabela 1: Etiologia infecciosa da mastite subclínica ovina aos 14 dias de lactação e ao desmame na Lactação 1

\begin{tabular}{|c|c|c|c|c|c|c|}
\hline \multirow[b]{2}{*}{ Micro-organismos } & \multicolumn{2}{|c|}{14 dias } & \multicolumn{2}{|c|}{ Desmame } & \multicolumn{2}{|c|}{ Total } \\
\hline & $\mathbf{N}$ & $\%$ & $\mathbf{N}$ & $\%$ & $\mathbf{N}$ & $\%$ \\
\hline $\mathrm{ECN}^{1}$ & 46 & 18,9 & 21 & 10,8 & 67 & 15,3 \\
\hline Staphylococcus aureus & 6 & 2,5 & 3 & 1,6 & 9 & 2,1 \\
\hline Coliforme & 5 & 2,1 & 3 & 1,6 & 8 & 1,8 \\
\hline $\mathrm{ECP}^{2}$ & 0 & 0,0 & 5 & 2,6 & 5 & 1,1 \\
\hline Corynebacterium spp & 2 & 0,8 & 0 & 0,0 & 2 & 0,5 \\
\hline Streptococcus spp. & 1 & 0,4 & 3 & 1,6 & 4 & 0,9 \\
\hline $\mathrm{ECN}+$ Corynebacterium spp. & 1 & 0,4 & 0 & 0,0 & 1 & 0,2 \\
\hline $\mathrm{ECN}+$ Coliforme & 1 & 0,4 & 1 & 0,5 & 2 & 0,5 \\
\hline Micrococcus spp. & 1 & 0,4 & 0 & 0,0 & 1 & 0,2 \\
\hline $\mathrm{ECP}+\mathrm{ECN}$ & 0 & 0,0 & 1 & 0,5 & 1 & 0,2 \\
\hline Amostras Negativas & 180 & 74,1 & 157 & 80,9 & 337 & 77,1 \\
\hline Total de amostras & 243 & 100,0 & 194 & 100,0 & 437 & 100,0 \\
\hline
\end{tabular}

Em ambos os períodos, aos 14 dias de lactação e ao desmame, os estafilococos coagulase-negativos foram predominantes com percentuais de isolamento de $18,9 \%$ e $10,8 \%$, respectivamente, seguidos por S. aureus e estafilococos coagulase-positivos aos 14 dias de lactação e ao desmame, respectivamente. Estafilococos coagulase-positivos foram isolados somente ao desmame, sendo menos frequentes que $S$. aureus e coliformes quando considerados os dois períodos de forma conjunta. Cento e oitenta $(74,1 \%)$ e $157(80,9 \%)$ amostras de leite não apresentaram isolamento microbiológico na segunda semana de lactação e à secagem (desmama das crias), respectivamente. 
Na Lactação 2, o gênero Staphylococcus ainda permaneceu como o de maior ocorrência (Tabela 2). Enquanto na Lactação 1 foram isolados em 85 (85,0\%) metades mamárias com mastite, na Lactação 2 foram isolados em $87(74,4 \%)$ glândulas mastíticas.

Tabela 2: Etiologia infecciosa da mastite subclínica ovina aos 14 e 52 dias de lactação e ao desmame dos cordeiros na lactação 2

\begin{tabular}{lcccccccc}
\hline & \multicolumn{2}{c}{$\mathbf{1 4}$ dias } & \multicolumn{2}{c}{ 52 dias } & \multicolumn{2}{c}{ Desmame } & \multicolumn{2}{c}{ Total } \\
\cline { 2 - 10 } Micro-organismos & $\mathbf{N}$ & $\mathbf{\%}$ & $\mathbf{N}$ & $\mathbf{\%}$ & $\mathbf{N}$ & $\mathbf{\%}$ & $\mathbf{N}$ & $\mathbf{\%}$ \\
\hline ECN $^{1}$ & 19 & 12,6 & 16 & 6,2 & 20 & 8,5 & 55 & 8,5 \\
Staphylococcus aureus & 7 & 4,6 & 7 & 2,7 & 4 & 1,7 & 18 & 2,7 \\
Coliformes & 6 & 4,0 & 6 & 2,3 & 4 & 1,7 & 16 & 2,5 \\
ECP $^{2}$ & 5 & 3,3 & 4 & 1,6 & 4 & 1,7 & 13 & 2,0 \\
Streptococcus spp. & 1 & 0,7 & 3 & 1,2 & 8 & 3,4 & 12 & 1,9 \\
Corynebacterium spp. & 0 & 0,0 & 0 & 0,0 & 1 & 0,4 & 1 & 0,2 \\
Micrococcus spp. & 0 & 0,0 & 0 & 0,0 & 1 & 0,4 & 1 & 0,2 \\
ECN+ Coliformes & 0 & 0,0 & 0 & 0,0 & 1 & 0,4 & 1 & 0,2 \\
Amostras Negativas & 113 & 74,8 & 221 & 85,9 & 193 & 81,8 & 527 & 81,8 \\
\hline Total de amostras & $\mathbf{1 5 1}$ & $\mathbf{1 0 0 , 0}$ & $\mathbf{2 5 7}$ & $\mathbf{1 0 0 , 0}$ & $\mathbf{2 3 6}$ & $\mathbf{1 0 0 , 0}$ & $\mathbf{6 4 4}$ & $\mathbf{1 0 0 , 0}$ \\
\hline${ }^{1}$ Estafilococos coagulase-negativos. & & & & & & & &
\end{tabular}

Os percentuais de amostras de leite negativas após os exames microbiológicos (Tabela 2) permaneceram semelhantes à "Lactação 1", entre 74,8\% e 85,9\% das amostras. Apesar de a avaliação da capacidade diagnóstica do CMT não ter sido objeto desse estudo, as amostras classificadas como negativas nas duas tabelas anteriores representam, em sua maioria, metades mamárias não reagentes ao teste. Reforça-se que somente resultados conjuntos de positividade ao CMT e identificação microbiana foram usados para considerar uma metade mamária como positiva para a mastite subclínica e, assim, se estudar a evolução da doença objetivada nesse trabalho.

Em estudo realizado com ovelhas Santa Inês no estado de São Paulo, 75,9\% das amostras de leite apresentaram resultados negativos nas provas bacteriológicas para o diagnóstico da mastite ${ }^{(2)}$. No Canadá, de um total de 697 amostras de leite, $82 \%$ foram negativas, enquanto em outras $17 \%$ foi isolado somente um tipo de micro-organismo e em $1 \%$ houve isolamentos de dois tipos bacterianos. Estafilococos coagulase-negativos e $S$. aureus foram isolados em casos de mastite subclínica por Arsenault et al. ${ }^{(13)}$. No presente trabalho, as associações entre micro-organismos não ultrapassaram $1 \%$ do total de amostras investigadas nas lactações "1" e "2" (0,92\% e 0,16\%, respectivamente).

Segundo Drescher et al. ${ }^{(14)}$, estafilococos foram os micro-organismos de maior ocorrência em casos de mastite subclínica ovina em animais de aptidão mista na região oeste de Santa Catarina (31,4\%). Esses autores também relataram isolamentos bacteriológicos de coliformes em casos subclínicos, de forma semelhante ao presente estudo, enquanto o percentual de amostras negativas nos exames microbiológicos foi inferior $(53,4 \%)$.

A evolução da mastite subclínica em uma mesma lactação pode ser visualizada na Tabela 3, de acordo com os períodos da lactação. 
Tabela 3: Evolução da mastite subclínica em rebanho ovino da raça Santa Inês entre 14 e 52 dias de lactação e entre 52 dias e o desmame

\begin{tabular}{|c|c|c|c|c|c|c|}
\hline \multirow[b]{2}{*}{ Evolução dos casos } & \multicolumn{6}{|c|}{ Períodos da lactação } \\
\hline & $\begin{array}{c}\text { Período } \\
\text { inicial }^{\mathrm{a}}\end{array}$ & $\%$ & $\begin{array}{c}\text { Período } \\
\text { finalb }^{b}\end{array}$ & $\%$ & Total & $\%$ \\
\hline Manutenção da mastite subclínica & 20 & 54,1 & 29 & 65,9 & 49 & 60,5 \\
\hline Casos novos de mastite subclínica & 4 & 10,8 & 14 & 31,8 & 18 & 22,2 \\
\hline Cura espontânea & 13 & 35,1 & 1 & 2,3 & 14 & 17,3 \\
\hline Total & 37 & 100,0 & 44 & 100,0 & 81 & 100,0 \\
\hline
\end{tabular}

Houve a predominância de ovelhas que se mantiveram com mastite subclínica entre 14 e 52 dias após o parto e do $52^{\circ}$ dia até o final da lactação (ao desmame). Apesar do maior número de casos em que houve manutenção do quadro de mastite subclínica nos dois períodos, quando comparado aos casos novos, encontrou-se diferença significativa $(\mathrm{P}<0,01)$ somente entre o grupo que apresentou cura espontânea com os demais grupos.

Com a evolução do período lactacional das ovelhas, a possibilidade de o animal sadio adquirir mastite subclínica infecciosa ou de o animal com mastite se manter infectado comumente se eleva, com redução dos casos de cura espontânea quando não são adotadas medidas de controle contra a mastite, como foi o ocorrido no rebanho estudado. Assim, de acordo com os valores apresentados na Tabela 3, os percentuais para os casos de manutenção da doença e de casos novos no "Período Final" foram superiores aos do "Período inicial".

Dentre os 13 casos de cura espontânea no período inicial, ou seja, cura da mastite sem a utilização de qualquer tipo de tratamento, nove $(69,2 \%)$ estavam relacionados com animais na segunda ordem de parição, enquanto dois $(15,4 \%)$ casos eram de ovelhas na terceira ordem de parto. Outras duas ovelhas apresentavam mais de três lactações. Mavrogianni et al. ${ }^{(15)}$ consideraram não haver diferenças entre fêmeas primíparas e multíparas quanto aos riscos de ovelhas adquirirem mastite. Porém, maior número de animais seria necessário para que relações epidemiológicas fossem mais bem estabelecidas no presente trabalho ou quanto à maior possibilidade de se tornarem doentes ou de apresentarem cura espontânea, conforme a evolução do número de parições dos animais.

O acompanhamento dos casos de mastite em um rebanho ovino pode ser útil para técnicos e produtores, como uma fonte de decisão para a efetivação de medidas de controle da doença. As condições ambientais às quais os animais estavam submetidos nesse período podem ter facilitado a ocorrência de diferentes agentes infecciosos responsáveis por novas infecções e menor ocorrência de curas espontâneas. No decorrer da fase compreendida entre os 52 dias pós-parto e o desmame houve redução da umidade relativa do ar média nos meses de julho e agosto de 2010, quando comparados com os meses de maio e junho. Em 13 dias do mês de agosto, a umidade relativa foi inferior a 50\%, enquanto de maio a julho, esse percentual abaixo dos $50 \%$ foi verificado apenas em um dia do mês de julho. Alteração aparente nos dados climáticos nesse período foi verificada também para os índices de precipitação pluviométrica, que foram reduzidos em 92,6\% quando os animais entraram na fase de avaliação a partir dos 52 dias pós-parto. 
Esses achados parecem contrariar resultados relatados para a mastite bovina, segundo os quais os riscos de infecção por $S$. aureus pareceram aumentar com a maior quantidade de chuvas, provavelmente pela maior dificuldade em alcançar condições higiênicas adequadas ${ }^{(16)}$. Entretanto, ressalta-se que as condições de manejo entre as duas espécies é diferente e os micro-organismos predominantes no presente trabalho são espécies de estafilococos coagulase-negativos, diferentemente do $S$. aureus.

A evolução dos casos de mastite subclínica infecciosa também foi analisada quando comparadas as duas lactações (Tabela 4). Nenhuma diferença significativa foi observada ( $\mathrm{P}>0,05)$.

Tabela 4: Evolução da mastite subclínica no decorrer de duas lactações em rebanho ovino da raça Santa Inês

\begin{tabular}{lccccccccc}
\hline & \multicolumn{8}{c}{ Períodos da lactação } \\
\cline { 2 - 10 } Evolução dos casos & $\mathbf{A}^{\mathbf{1}}$ & $\mathbf{0}$ & $\mathbf{B}^{\mathbf{2}}$ & $\mathbf{\%}$ & $\mathbf{C}^{\mathbf{3}}$ & $\mathbf{\%}$ & Tota & $\mathbf{\%}$ \\
& & & & & & & & $\mathbf{1}$ & \\
\hline Manutenção dos casos & 28 & 62,2 & 29 & 53,7 & 35 & 63,6 & 92 & 59,8 \\
Casos novos & 9 & 20,0 & 11 & 20,4 & 9 & 16,4 & 29 & 18,8 \\
Cura espontânea & 8 & 17,8 & 14 & 25,9 & 11 & 20,0 & 33 & 21,4 \\
\hline Total & $\mathbf{4 5}$ & $\mathbf{1 0 0 , 0}$ & $\mathbf{5 4}$ & $\mathbf{1 0 0 , 0}$ & $\mathbf{5 5}$ & $\mathbf{1 0 0 , 0}$ & $\mathbf{1 5 4}$ & $\mathbf{1 0 0 , 0}$ \\
\hline${ }^{1}$ Comparação feita entre os 14 dias da Lactação 2 e a lactação anterior. \\
${ }^{2}$ Comparação feita entre os 52 dias da Lactação 2 e a lactação anterior. \\
${ }^{3}$ Comparação feita entre o desmame da Lactação 2 e a lactação anterior.
\end{tabular}

Entre duas lactações observou-se também que a manutenção dos casos de mastite foi predominante nos três períodos apresentados na Tabela 4. Em rebanhos cuja produção de leite não é o principal objetivo econômico, a manutenção de animais em pastos mal manejados ou condições nutricionais insuficientes fornecidas por uma dieta desequilibrada relacionam-se com uma maior possibilidade da glândula mamária ovina se tornar infectada, com manutenção dos casos de mastite subclínica nas diferentes lactações. No rebanho estudado, a escassa mão de obra prejudicou o manejo das pastagens durante o período de colheita de amostras.

Os micro-organismos de maior ocorrência no presente estudo foram estafilococos coagulasenegativos, bactérias heterogêneas comumente encontradas no ambiente em que as ovelhas permanecem e facilmente transferidas entre os hospedeiros ${ }^{(13)}$. Estes micro-organismos são frequentemente encontrados nas mãos das pessoas e no ambiente ${ }^{(15)}$.

Segundo Gougolis et al. ${ }^{(17)}$, a mastite subclínica resulta em uma redução da produção de leite que é secretado pelas glândulas mamárias e afeta a preferência dos cordeiros, ao ponto de eles preferirem mamar nas glândulas mamárias sadias. Tema relevante para estudos posteriores é a possibilidade de cordeiros que mamam em mamas sadias poderem transmitir micro-organismos a elas. Esta prática pode corroborar com a manutenção de fontes de infecção dentro de um rebanho, mesmo quando não há desenvolvimento da mastite no animal. 


\section{Conclusões}

Os estafilococos coagulase-negativos foram os agentes etiológicos mais frequentes da forma subclínica da mastite. Houve tendência à manutenção da mastite subclínica no rebanho, com poucas curas espontâneas na segunda lactação a partir dos 52 dias. Diferentes fontes de transmissão podem ter atuado para a transferência de bactérias entre as metades mamárias e a ocorrência de reinfecções.

\section{Agradecimentos}

Agradecemos à Fundação de Amparo à Pesquisa do Estado de São Paulo / FAPESP - Processos n ${ }^{\circ}$ 2007/56558-9 e 2008/11034-5.

\section{Referências}

1.Waage S, Vatn S. Individual animal risk factors for clinical mastitis in meat sheep in Norway. Preventive Veterinary Medicine. 2008;87:229-243.

2.Nunes GR, Blagitz MG, Freitas CB, Souza FN, Ricciardi M, Stricagnolo CR, Sanches BGS, Azedo MR, Sucupira MCA, Della Libera AMMP. Avaliação de indicadores inflamatórios no diagnóstico da mamite ovina. Arquivos do Instituto Biológico. 2008; 75(3):271-278.

3.Almeida MZPRB, Oliveira LGL, Afonso JAB, Lázaro NS, Mendonça CL. Etiologia e sensibilidade bacteriana da mastite subclínica em ovelhas da raça Santa Inês no Agreste Meridional do Estado de Pernambuco. Archives of Veterinary Science. 2007;12 (supl.):116.

4.Mavrogianni VS, Menzies PI, Fragkou IA, Fthenakis GC. Principles of mastitis treatment in sheep and goats. Veterinary Clinics of North America: Food Animal Practice. 2011;27(1):115-120.

5.Moroni P, Pisoni G, Varisco G, Boettcher P. Effect of intramammary infection in Bergamasca meat sheep on milk parameters and lamb growth. Journal of Dairy Research. 2007;74:340-344.

6.Bolsanello RX, Hartman M, Domingues PF, Mello Júnior AS, Langoni H. Etiologia da mastite em ovelhas Bergamácia submetidas a ordenha mecânica, criadas em propriedade de Botucatu, SP. Veterinária e Zootecnia. 2009;16:221-227.

7.Hariharan H, Donachie W, Macaldowie C, Keefe G. Bacteriology and somatic cell counts in milk samples from ewes on a Scottish farm. The Canadian Journal of Veterinary Research. 2004;68:188192.

8.Schalm OW, Noorlander D O. Experiments and observations leading to development of the California Mastitis Test. Journal of American Veterinary Medical Association. 1957;130(5):199-207.

9.Koneman EW, Allen SD, Janda WM, Schreckenberger PC. Winn JR WCW. Diagnóstico microbiológico - Texto e atlas colorido. 5. ed. Rio de Janeiro: Medsi. 2001.1465p.

10.Ariznabarreta A, Gonzalo C, Primitivo FS. Microbiological quality and somatic cell count of ewe milk with special reference to Staphylococci. Journal of Dairy Science. 2002;85(6):1370-1375. 
11.Gonzalo C, Ariznabarreta A, Carriedo JA, Primitivo FS. Mammary pathogens and their relationship to somatic cell count and milk yield losses in dairy ewes. Journal of Dairy Science. 2002;85(6):1460-1467.

12.Sampaio IBM. Estatística aplicada à experimentação animal. Belo Horizonte: Fundação de Ensino e Pesquisa em Medicina Veterinária e Zootecnia. 1998.221p.

13.Arsenault J, Dubreuil P, Higgins R, Belanger D. Risk factors and impacts of clinical and subclinical mastitis in commercial meat-producing sheep flocks in Quebec, Canada. Preventive Veterinary Medicine. 2008;87:373-393.

14.Drescher G, Mattiello SP, Peixoto RM, Vargas AC, Maciel MN, Costa MM. Caracterização bioquímica e perfil de sensibilidade aos antimicrobianos de agentes bacterianos isolados de mastite subclínica ovina na região oeste de Santa Catarina. Ciência Animal Brasileira. 2010;11(1):188-193.

15.Mavrogianni VS, Cripps PJ, Fthenakis GC. Bacterial flora and risk of infection of the ovine teat duct and mammary gland throughout lactation. Preventive Veterinary Medicine. 2007;79:163-173.

16.Zafalon LF, Langoni H, Benvenutto F, Castelani L, Broccolo CR. Aspectos epidemiológicos da mastite bovina causada por Staphylococcus aureus. Veterinária e Zootecnia. 2008;15(1):56-65.

17.Gougoulis DA, Kyriazakis I, Papaioannou N, Papadopoulos E, Taitzoglou IA, Fthenakis GC. Subclinical mastitis changes the patterns of maternal-offspring behaviour in dairy sheep. The Veterinary Journal. 2008;176:378-384. 